\title{
Long Term Water Storage Deteriorates Bonding of Composite Resin to Alumina and Zirconia Short Communication
}

\author{
T.T. Heikkinen ${ }^{1}$, J.P Matinlinna ${ }^{2}$, P.K. Vallittu ${ }^{1, *}$ and L.V.J. Lassila ${ }^{1}$ \\ ${ }^{I}$ Department of Biomaterials Science and Turku Clinical Biomaterials Centre - TCBC, Institute of Dentistry, University \\ of Turku, Turku, Finland \\ ${ }^{2}$ University of Hong Kong, Faculty of Dentistry, 4/F Dental Materials Science, The Prince Philip Dental Hospital, Hong Kong
}

\begin{abstract}
Objective of this study was to evaluate the effects of long term water storage and ageing on the bond strength of resin composite cement to yttria-stabilized zirconium dioxide (zirconia) and dialuminium trioxide (alumina). Substrate specimens of alumina and zirconia were air particle abraded with dialuminium trioxide before priming and application of composite resin. Priming was made with gamma metharyloxy-trimethoxysilane or acryloxypropyl-trimethoxysilane monomer after which the intermediate dimethacrylate resin was applied and photopolymerized. This was followed by curing particulate composite resin cement (Relyx ARC) to the substrate as a resin stub. The ageing methods of the specimens $(\mathrm{n}=6)$ were: (1) they stored four years in $37 \pm 1^{\circ} \mathrm{C}$ distilled water, (2) thermocycled 8000 times between $55 \pm 1^{\circ} \mathrm{C}$ and $5 \pm 1^{\circ} \mathrm{C}$, (3) stored first in water for four years and then thermocycled. Specimens which were stored dry, were used as controls. Bonding of composite resin was measured by shear-bond strength test set-up. Both thermocycling and long-term water storage decreased significantly shear bond strength values compared to the control group (from the level of $20 \mathrm{MPa}$ to 5 $\mathrm{MPa}$ ) regardless of the used primer or the type of the substrate. Combination of four years water storage and thermocyling reduced the bond strength even more, to the level of two to three megapascals. In can be concluded that water storage and thermocycling itselves, and especially combination of water storage and thermocycling can cause considerable reduction in the bond strength of composite resin cement to alumina and zirconia.
\end{abstract}

Keywords: Zirconia, alumina, bond strength, composite.

\section{INTRODUCTION}

During recent years all-ceramics, e.g. yttria $\left(\mathrm{Y}_{2} \mathrm{O}_{3}\right)$ stabilized zirconium dioxide $\left(\mathrm{ZrO}_{2}\right.$, zirconia) and dialuminum trioxide $\left(\mathrm{Al}_{2} \mathrm{O}_{3}\right.$ alumina) based fixed dental prostheses (FDPs), have been started to be used as substitutes for gold alloy based FDPs because of their biocompatibility and cosmetic values. A wide range of other clinical applications, e.g. root canal posts, crowns, veneers, implants and implant abutments are available as well. Clinical success with these materials is based on proper mechanical interlocking of the device to tooth substance and adhesion of composite resin luting cement to the ceramic and tooth substance. The effects of airborne particle abrasive, tribochemical or combined treatments with or without silanizing have been evaluated in numerous studies to improve bonding of composites to alumina and zirconia [1-5]. However, there is lack of information whether or not the long-term water immersion itself can deteriorate bonding by hydrolysis. Thus, the aim of this piece of work was the evaluate effect of water storage and thermocyling as such and in combination to the bond strength of composite resin to alumina and zirconia.

*Address correspondence to this author at the Institute of Dentistry, University of Turku, Lemminkäisenkatu 2, FI-20520 Turku, Finland,

Tel: +358-2-3338332; Fax: +358-2-3338330; Email: pekka.vallittu@utu.fi

\section{MATERIALS AND METHODS}

Study design simulates clinical situation where ceramic construction is cemented to tooth surface, and especially interface of luting cement to ceramic. Zirconia (Procera Zirconia, Nobel Biocare, Göteborg, Sweden) and alumina (Procera Alumina, Nobel Biocare, Göteborg, Sweden) rhombic specimens $\left(2 \times 10 \times 10 \mathrm{~mm}^{3}\right)$ were embedded into cylinders filled with acrylic resin to form the bonding specimen for the composite resin stubs. Substrates were air particle abraded with $\mathrm{Al}_{2} \mathrm{O}_{3}$ (Korox ${ }^{\circledR} 50$, Bego, Bremen, Germany) with a diameter of $50 \mu \mathrm{m}$ for $10 \mathrm{~s}$ with an aiborne particle abrasion device (Rocatec ${ }^{\mathrm{TM}}, 3 \mathrm{M}$ ESPE, Seefeld, Germany). Air pressure of $300 \mathrm{kPa}$ was used and the distance between the tip of the blasting device and the ceramic surface was $10 \mathrm{~mm}$. Substrates were primed with two primers (silane and phosphate monomer) before application of the light curing intermediate resin and composite resin [5]. Study groups were as follows:

Group AM: The alumina substrates were primed with a gamma metharyloxy-trimethoxysilane (MPS) (EspeSil, 3M ESPE, Seefeld, Germany) and an intermediate resin (Adper $^{\mathrm{TM}}$ Scotchbond ${ }^{\mathrm{TM}}$ 1, 3M ESPE, Seefeld, Germany) was applied on the surfaces for $10 \mathrm{~s}$, air-dried for $5 \mathrm{~s}$ and photopolymerized for $10 \mathrm{~s}$ (Optilux-501, Kerr, Orange CA, USA). Wavelength maximum of the light was $495 \mathrm{~nm}$ and the light intensity was $550 \mathrm{~mW} / \mathrm{cm}^{2}$. 


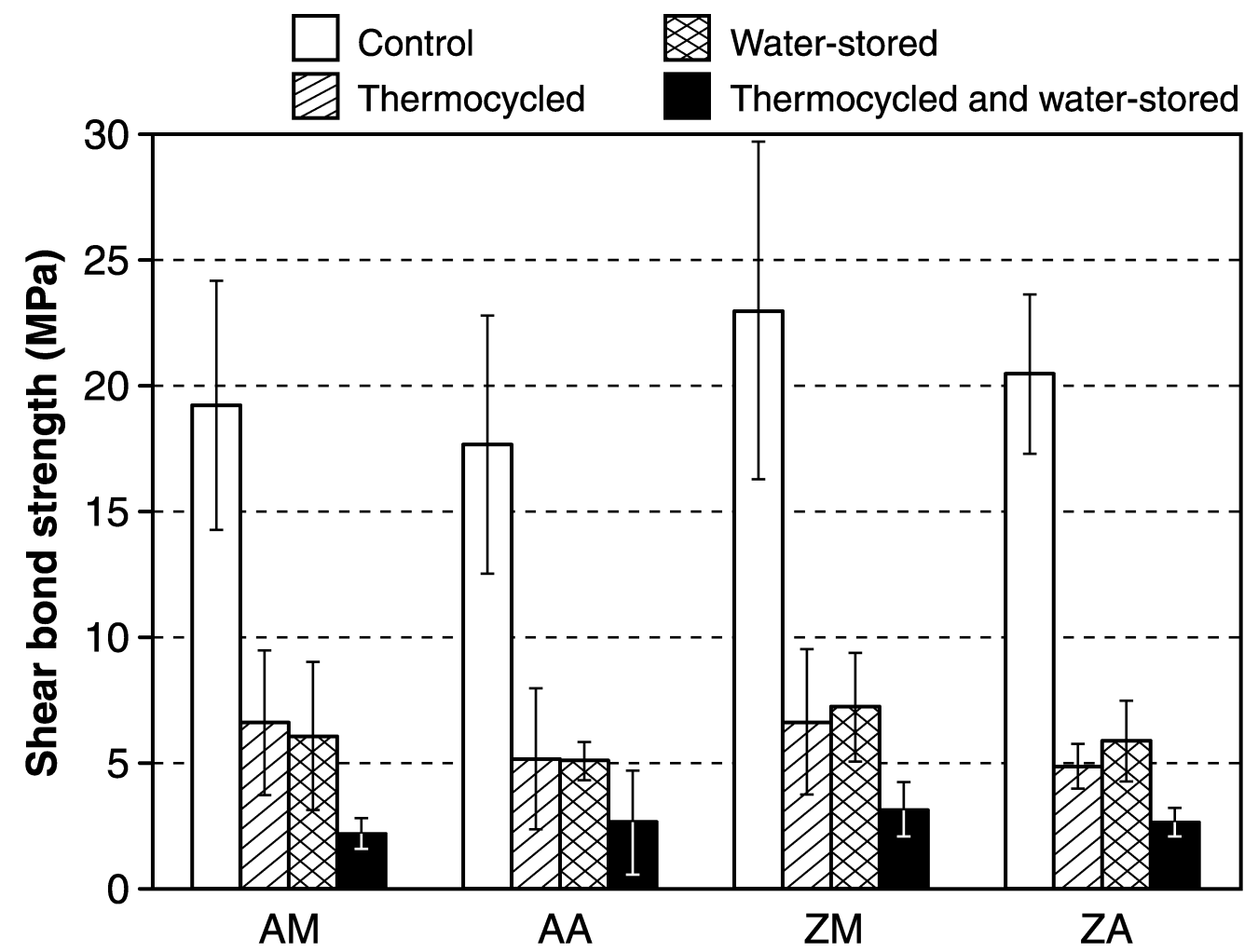

Fig. (1). Mean values of shear bond strengths (MPa) of composite resin cement to alumina (AM and AA) and zirconia (ZM and ZA) with two different ceramic primers and four years water-storage. Vertical lines represents standard deviations.

Group AA: the alumina substrates were primed with 1.0 vol-\% solution of 3-acryloxypropyl-trimethoxysilane (ACPS) was prepared in the acidified ethanol-water solution. 95.0 vol- $\%$ ethanol and 5.0 vol-\% de-ionized water (milli-Q water) mixture. $\mathrm{pH}$ was adjusted with $1 \mathrm{M}$ acetic acid to 4.5 and then the solvent system was allowed to stabilize for $24 \mathrm{~h}$ at room temperature. An intermediate resin (Adper $^{\mathrm{TM}}$ Scotchbond ${ }^{\mathrm{TM}}$ 1, 3M ESPE, Seefeld, Germany) was applied on the surfaces for $10 \mathrm{~s}$, air-dried for $5 \mathrm{~s}$ and photo-polymerized for $10 \mathrm{~s}$ (Optilux-501, Kerr, Orange CA, USA). Wavelength maximum of the light was $495 \mathrm{~nm}$ and the light intensity was $550 \mathrm{~mW} / \mathrm{cm}^{2}$ [5].

Group ZM: the zirconia substrates were primed and treated with the intermediate resin as in the Group AM.

Group ZA: the zirconia substrates were primed and treated with the intermediate resin as in the Group AA.

Resin composite cement stubs (RelyX Arc, 3M ESPE, Seefeld, Germany) (diameter $3.6 \mathrm{~mm}$, height $4.0 \mathrm{~mm}$ ) were added to each of the substrates and photo-polymerized for 40 s (Optilux-501, Kerr, Orange CA, USA). Relyx ARC cement is based on silane treated silica particles and resin system based on triethylene glycol dimethacrylate (TEGDMA) and bisphenola-a-glycidyldimetharylate (bisGMA). Thermocycling of 8000 times between $55 \pm 1^{\circ} \mathrm{C}$ and $5 \pm 1^{\circ} \mathrm{C}$, water storage for four years at $37^{\circ} \mathrm{C}$ and thermocycling combined with the water storage of four years were used as ageing methods. Dry specimens were used to form a control group. The shear bond strengths of the composite resin stubs to the substrates were measured with a crosshead speed of 1.0 $\mathrm{mm} / \mathrm{min}$ (Lloyd Instruments LRX Material Testing Machine,
Lloyd Instruments, Fareham, England) with a parallel knifeedge blade touching the interface of the ceramic and resin composite cylinder [5]. Multi-factorial analysis of variances (ANOVA) was used as a statistical method.

\section{RESULTS}

Both thermocycling and water storage decreased significantly $(p<0.001)$ the shear bond strength values compared to the control group (from the level of $20 \mathrm{MPa}$ to $5 \mathrm{MPa}$ ) regardless of the used primer or the type of substrate (Fig. 1). Combination of four years water storage and thermocyling reduced the bond strength even more, to the level of two to three megapascals. There were no statistical differences of bond strengths between the used silanes or between the thermocyling or four-years water storage $(p>0.05)$.

\section{DISCUSSION}

The present study was originally planned in order to investigate the effect of long-term water storage on shear bond strength compared with other commonly used in vitro ageing method, namely thermocycling [6]. Thermocycling and water immersion for various periods of time have been used in numerous studies as an artificial ageing method [1-5]. On the other hand, it is also known the silane coupling agents after being polycondensated and formed initially durable bond between hydroxyl covered ceramic substrate and the intermediate resin, are prone for hydrolysis which can deteriorate adhesion in longer term $[2,7,8]$. This study, regardless of its limitation of using shear bond strength test, suggested that water immersion as such can cause considerable reduction in bonding of composite cement to alumina and zirconia. This 
is likely due to hydrolysis of polysiloxane network between the ceramic substrate and the polymerized intermediate resin. On the other hand, thermocycling caused repeated thermal expansion and contraction of the materials, which likely caused fatigue at the interphase, which resulted in reduction of bonding values. Combination of the two mechanisms of weakening of bond, i.e. hydrolysis and fatigue, demonstrated the highest drop in the bond strength found in the present study. Clinically, reduced bonding values by time could cause loosening of FDPs of different kinds. Based on our experience, critical shear bond strength for clinical success is estimated to be $18-20 \mathrm{MPa}$ taking into consideration bonding surface area and direction and magnitude of stress. Thus, only control samples would have provided reliable bonding.

\section{CONFLICT OF INTEREST}

Pekka Vallittu consults Stick Tech LTD in research and development.

\section{ACKNOWLEDGEMENTS}

The authors wish to thank Nobel Biocare and 3M ESPE for generous supply of test materials. This investigation was financially supported by grants from the TEKES (Finnish
National Agency for Technology and Innovation) and the Finnish Dental Society Apollonia. The research was a part of the activity of BioCity Turku Biomaterials Research Program (www.biomaterials.utu.fi).

\section{REFERENCES}

[1] Kern M, Wegner SM. Bonding to zirconia ceramic: adhesion methods and their durability. Dent Mater 1998; 14: 64-71.

[2] Matinlinna JP, Lassila LVJ, Özcan M, Yli-Urpo A, Vallittu PK. An introduction to silanes and their clinical applications in dentistry. Int J Prosthodont 2004; 17: 155-64.

[3] Özcan M, Vallittu PK. Effect of surface conditioning methods on the bond strength of luting cement to ceramics. Dent Mater 2003; 19:725-31.

[4] Aboushelib MN, Kleverlaan CJ, Feilzer AJ. Selective infiltration etching technique for a strong and durable bond of resin cements to zirconia-based materials. J Prosthet Dent 2007; 98: 379-88.

[5] Heikkinen TT, Matinlinna JP, Vallittu PK, Lassila LVJ. Effect of primers and resins on the shear bond strength of resin composite to zirconia. SRX Dent doi:103814/2010/295137.

[6] Gale MS, Darvell BW. Thermal cycling procedures for laboratory testing of dental restorations. J Dent 1999; 27: 89-99.

[7] Rosen MR. From treating solution to filler surface and beyond. the life history of a silane coupling agent. J Coat Technol 1978; 50: 758 .

[8] Söderholm K-JM, Shang SW. Molecular orientation of silane at the surface of colloidal silica. J Dent Res 1993; 72: 1050-4.

(C) Heikkine et al.; Licensee Bentham Open.

This is an open access article licensed under the terms of the Creative Commons Attribution Non-Commercial License (http://creativecommons.org/licenses/by-nc/3.0/) which permits unrestricted, non-commercial use, distribution and reproduction in any medium, provided the work is properly cited. 